\title{
Analysis of bottom sediments of small lakes in Central Karelia
}

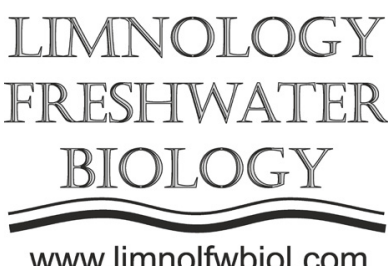

\begin{abstract}
Myasnikova N.A.*
Northern Water Problems Institute of the Karelian Research Centre of the Russian Academy of Sciences, 50 Al. Nevsky Ave., 185030 Petrozavodsk, Russia

ABSTRACT. Data on the particle size distribution of bottom sediments in small lakes of Central Karelia are presented. Sediment fraction sizes in the study area - Lake Torosjarvi - varied from very fine sand to silty clay. The prevalent fraction was coarse silt. The paleo-hydrodynamic environment for sedimentation of the rocks was analyzed using the genetic diagram by R. Passega. Three intervals were characterized as turbidite deposits, the rest of the intervals fell in the zone of deposits left by low-velocity streams. The study of changes in sedimentation in Lake Torosjarvi suggests there occurred five shifts in the dynamic water regimes in the course of the lake formation.
\end{abstract}

Keywords: bottom sediments, particle size distribution, lake.

An important task in lake research, especially studies of bottom sediments, is thorough investigation of past changes in the environment and climate, which is a prerequisite for understanding modern climate change and assessing it adequately. One of the ways to explore paleoclimatic and paleogeographic variability is a comprehensive study of sediment cores from waterbodies. At present, one of the main methods of studying bottom sediments is grain-size analysis, which allows typifying bottom sediments according to the accepted classification, determining the degree of their sorting, and assessing the paleo-hydrodynamic sedimentation environment.

The object of the study was Lake Torosjarvi, situated in the Medvezhyegorsky District of the Republic of Karelia. Lake Torosjarvi belongs to the White Sea drainage basin, and lies in the upper part of the Vyg River (White Sea-Baltic Canal) catchment, within the West Karelian Upland.

Grain-size analysis of bottom sediments from Lake Torosjarvi was performed for ten samples from a depth of $4.68-5.35$ meters. The bottom sediment fractions were classified into grain-size classes according to V.D. Lomtadze (1984). The grain-size analysis of bottom sediments from Lake Torosjarvi revealed a prevalence of the coarse silt fraction (0.01$0.05 \mathrm{~mm}$ ), which contributed $49 \%$ to $63 \%$. The sand fraction is represented by fine sand $(0.1-0.25 \mathrm{~mm})$, contributing $5 \%$ to $12 \%$, and very fine sand $(0.05-0.1$ $\mathrm{mm}$ ) with $21 \%$ to $39 \%$. The clay fraction occurred not in all sampling intervals, and accounted for ca. $1 \%$.

P. Trask (1932) suggested classifying all sediments into well-sorted $\left(\mathrm{S}_{0}=1.0-1.58\right)$, moderately sorted $\left(\mathrm{S}_{0}=1.58-2.12\right)$, and poorly sorted $\left(\mathrm{S}_{0}>2.12\right)$ according to the degree of their sorting.

Cumulative curves were plotted to calculate the sorting coefficient (So), asymmetry coefficient $\left(\mathrm{S}_{\mathrm{k}}\right)$, and coefficient $\mathrm{K}$ (Fig.). The cumulative curves and the coefficients were derived using the technique suggested by S.A. Koval and G.V. Wojciechowski (2001).

Bottom sediments of the studied core section (from 4.4-5.4 $\mathrm{m}$ depth) are mainly poorly sorted sediments (sorting coefficient $\mathrm{S}_{0}$ varies from 2.21 to 2.51). Samples in the depth intervals $4.68-4.69 \mathrm{~m}\left(\mathrm{~S}_{0}=\right.$ $2.0)$ and $5.24-5.25 \mathrm{~m}\left(\mathrm{~S}_{0}=2.09\right)$ represent moderately sorted sediments. The asymmetry coefficient for all the studied intervals has a positive value and varies from 1.1 to 1.62 , but mostly within the range of $1.38-1.51$. Hence, most of the bottom sediments tend to have a prevalence of the fine fraction, in particular coarse silt, the fraction size being 0.01-0.05 $\mathrm{mm}$.

A preliminary assessment of the paleohydrodynamic settings for sedimentation based on grain-size analysis findings was carried out using the Passega genetic diagram (Passega and Byramjee, 1969). Three intervals $(4.68-4.69 \mathrm{~m}, 5.04-5.05 \mathrm{~m}$ and 5.14$5.15 \mathrm{~m}$ ) fell into the zone of turbiditic deposits, while the remaining $4.71-4.81 \mathrm{~m}$ and 5.24-5.35 $\mathrm{m}$ intervals represented homogeneous suspended load sediment (deposited by low-velocity streams).

\section{Conclusions}

Monitoring of water bodies provides us with substantial amounts of data, which can be used to assess and describe of condition of the water body and to predict its future development. 


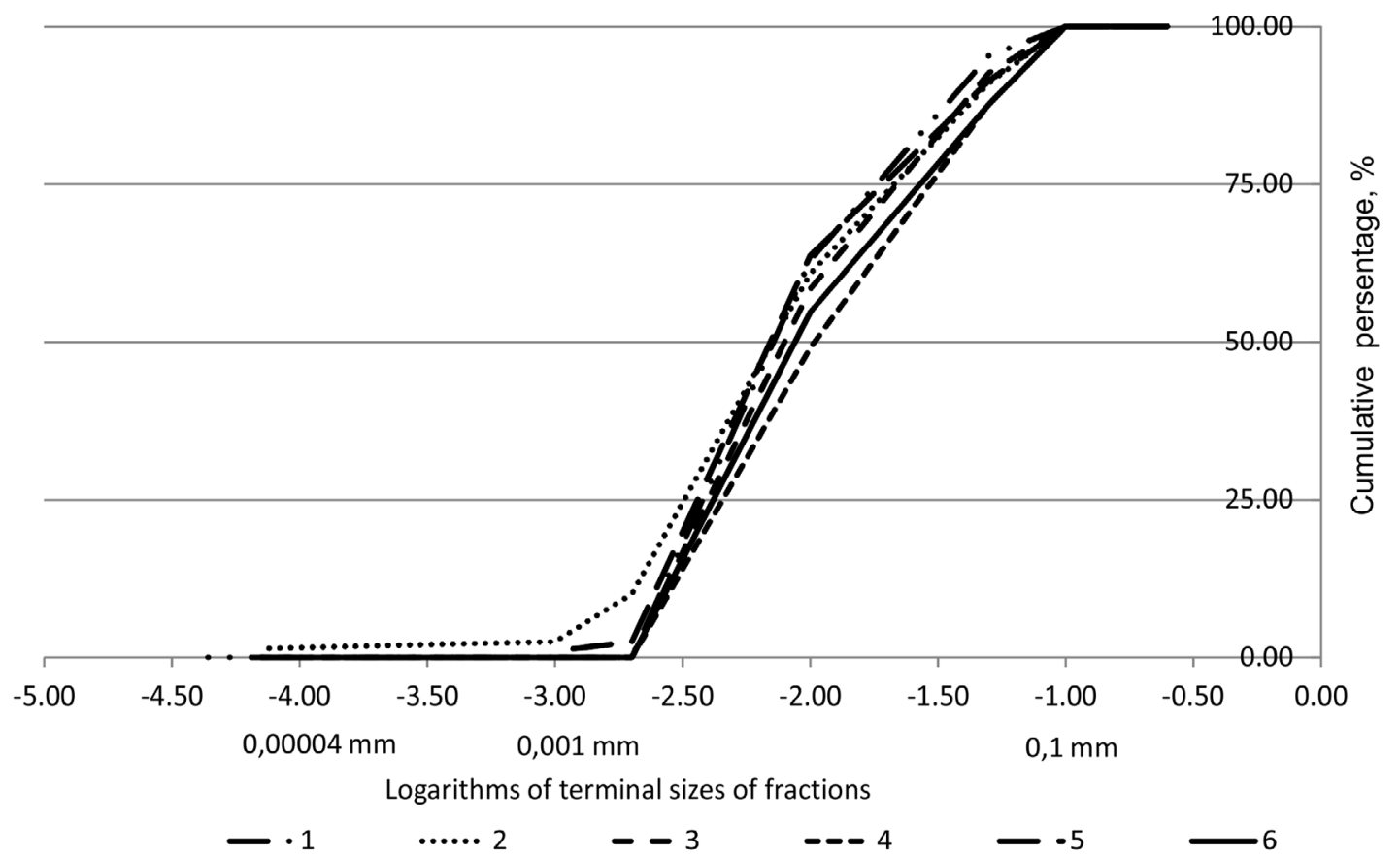

Fig. Diagram showing cumulative curves for sediment samples from Lake Torosjarvi: sampling intervals, m:
1. 4.68-4.69;
3. 4.76-4.77;
5. 5.24-5.25
2. $4.71-4.72$
4. $4.78-4.79$
6. $5.34-5.35$

Studies of bottom sediment samples from Lake Torosjarvi revealed a prevalence of the coarse silt fraction, which contributed $49.04 \%$ to $62.96 \%$.

The sorting coefficients calculated for the sediments from cumulative curve graphs reveal a low degree of sediments sorting in most of the samples.

The assessment of the paleo-hydrodynamic context for sedimentation of the rocks based on grainsize analysis showed that three intervals fell in the turbidite deposit zone, while the rest of the intervals were homogeneous suspended load sediments deposited by low-velocity streams.

A preliminary analysis of the sedimentation dynamics in the 4.4-5.4 $\mathrm{m}$ interval of the core from Lake Torosjarvi suggests the dynamic water regime has changed five times in the course of the lake formation.

\section{References}

Koval S.A., Wojciechowski G.V. Komp'yuternaya obrabotka rezul'tatov granulometricheskogo analiza i ikh geneticheskaya interpretatsiya [Computer processing of the results of grain-size analysis and their genetic interpretation]. 2001. Voronezh: VGU Publishing House. (in Russian)

Lomtadze V.D. Inzhenernaya geologiya. Inzhenernaya petrologiya [Engineering geology. Engineering petrology]. 1984. Leningrad: Nedra. (in Russian)

Passega R., Byramjee R. 1969. Grain-size image of clastic deposits. Sedimentology 13: 233-252.

Trask P.D. 1932. Origin and environment of source sediment of petroleum. Houston: Gulf Publishing Company. 